\title{
O ENSINO DE LIBRAS NA FORMAÇÃO DE PROFESSORES: FORMAS DE PERCEBER O SURDO E A LÍNGUA DE SINAIS
}

Hector Renan da Silveira Calixto ${ }^{\mathrm{i}}$

\begin{abstract}
Resumo: Este estudo objetiva analisar as formas de graduandos em Pedagogia e Geografia perceberem o surdo e a Língua Brasileira de Sinais (LIBRAS). Especificamente pretende-se: apresentar percepções dos alunos de licenciatura sobre surdos e LIBRAS antes de cursarem a disciplina LIBRAS e depois. Como metodologia utilizou-se o estudo de caso, com entrevistas semiestruturadas. Participaram da pesquisa 10 sujeitos, 4 antes da disciplina e 6 depois da disciplina. Conclui-se que, antes da disciplina a percepções era fortemente ancorada na visão clínico terapêuticas da surdez (surdo como deficiente, anormal e inferior) e LIBRAS uma linguagem e após a disciplina as percepções passaram a ser focadas na visão sócio antropológica (em que o surdo é visto como diferente) e a LIBRAS como língua legítima dos surdos brasileiros.
\end{abstract}

Palavras-chave: Língua Brasileira de Sinais. Surdez. Formação de professores.

\begin{abstract}
This study aims to analyze the forms of undergraduates in Pedagogy and Geography perceive the deaf and the Brazilian Sign Language (LIBRAS_. Specifically, it is intended to: present students' perceptions of deaf and LIBRAS before attending the LIBRAS discipline and afterwards. As methodology used was the case study, with semi-structured interviews. The participants were 10 subjects, 4 before they coursed the discipline and 6 after. It was concluded that prior to the discipline the perceptions were strongly anchored in the clinical view of deafness (deaf as deficient, abnormal and inferior) and LIBRAS as a language, after the discipline the perceptions became focused on the socio-anthropological vision (deaf as different) and LIBRAS as legitimate language of Brazilian deaf.
\end{abstract}

Keywords: Brazilian Sign Language. Deafness. Teacher training.

\section{Introdução}

O presente trabalho tem como objetivo analisar as percepções de graduandos em pedagogia e geografia sobre o surdo e a Libras. Destaco que o interesse por escrever sobre esta temática justifica-se pelo fato desta disciplina ser um componente curricular do curso de pedagogia, embasado no Decreto $n^{0} 5.626$ (BRASIL, 2005), que determina que os professores em formação tenham acesso aos conteúdos a respeito da Libras e do surdo, o que possibilita maiores reflexões e a construção de outras percepções a esse respeito.

A inclusão da disciplina de Libras no currículo das licenciaturas é algo relativamente recente em algumas instituições de ensino superior, mesmo após a obrigatoriedade desta disciplina ter sido instituída pelo Decreto $\mathrm{n}^{\circ} 5.626$ (BRASIL, 2005), que determina: 
Art. 3- A Libras deve ser inserida como disciplina curricular obrigatória nos cursos de formação de professores para o exercício do magistério, em nível médio e superior, e nos cursos de Fonoaudiologia, de instituições de ensino, públicas e privadas, do sistema federal de ensino e dos sistemas de ensino dos Estados, do Distrito Federal e dos Municípios.

§ 1o Todos os cursos de licenciatura, nas diferentes áreas do conhecimento, o curso normal de nível médio, o curso normal superior, o curso de Pedagogia e o curso de Educação Especial são considerados cursos de formação de professores e profissionais da educação para o exercício do magistério.

$\S 2$ o A Libras constituir-se-á em disciplina curricular optativa nos demais cursos de educação superior e na educação profissional, a partir de um ano da publicação deste Decreto (BRASIL, 2005, Art. $3^{\circ}$ ).

Em vista disso, as diversas instituições de ensino passaram a ter profissionais para o ensino da Libras em seu quadro funcional. Esses profissionais têm como objetivo ensinar os conceitos básicos da Libras, mas as ementas das disciplinas não são unificadas, sendo que cada instituição de ensino superior exerce sua autonomia em criar as ementas, e cada professor também exerce a mesma autonomia ao criar seu plano de curso para essas disciplinas.

Os surdos estão presentes na sociedade contemporânea, e são vistos e percebidos como sujeitos, por alguns como sujeitos diferentes e por outros como sujeitos deficientes. Assim, surgem os seguintes questionamentos: quais as percepções de graduandos em pedagogia e geografia sobre o surdo e a Libras e qual o efeito dessa disciplina nos cursos de licenciatura no que diz respeito a mudança de representações que os futuros professores possuem sobre o surdo e sobre a Libras?

Para responder a estes questionamentos realizamos este estudo que pretende apontar as possíveis mudanças na forma de perceber de futuros professores, a respeito do surdo e da Língua Brasileira de Sinais. A possível influência da disciplina de Libras na formação de professores é o objeto pesquisado e apresentado neste artigo, em forma de um estudo de caso, com participação de 10 alunos. A fim de contextualizar o tema, apresentamos como o surdo e a Libras vem sendo percebidos pela sociedade e quais as mudanças em relação a participação dos sujeitos surdos na educação e a função da Libras nessa inclusão educacional e social.

\section{O surdo e a Libras}

A concepção de surdez e do surdo tem uma trajetória histórica que remonta desde a idade antiga, entre os hebreus e gregos. Conforme apontado por Perlin (2002), os hebreus já apresentavam a ideia de integração dos surdos, e podemos perceber isso já nos mandamentos bíblicos presentes no Livro de Levíticos, capítulo 19, versículo 14 diz "não amaldiçoe um surdo 
nem ponha um obstáculo diante de um cego". Perlin (2002) relaciona isso com a aceitação do surdo de estar presente entre o seu povo.

\begin{abstract}
Notamos, aí, que, nesse povo, já existia o problema da exclusão do sujeito surdo, entretanto a forma de narrar essa legislação pode ser resumida a um apelo pela nãoexclusão social. [...] É curioso notar que o surdo recebeu do povo hebreu, através de um decreto, o reconhecimento como sujeito humano e, consequentemente, a sua permanência no interior desse próprio povo (PERLIN, 2002, p. 24).
\end{abstract}

Ainda na idade antiga, os gregos não tinham a mesma concepção que os hebreus, sendo que Perlin (2002, p. 27) aponta para o não reconhecimento dele enquanto sujeito, quando diz que "por não representar um sujeito produtivo, o surdo, naquela sociedade, tendia a ser excluído socialmente e, inclusive, tendia a ser um não-sujeito para a vida" Desta forma, acredita-se que muitos surdos tinha sua vida interrompida, como apontado por Perlin (2002, p. 27) que "todos os recém-nascidos - até a idade de três anos - que constituíam um peso potencial para o Estado, podiam ser sacrificados".

Desde a idade antiga até tempos modernos, a representação da surdez e do surdo vem mudando, tendo seu reconhecimento legal como sujeito, mas nem sempre como sujeito capaz ou compreendido com o participante da sociedade a qual está integrado.

Esta representação começa a mudar quando iniciam os caminhos para a valorização da língua de sinais, principalmente no processo de ensino dos surdos, tendo como precursor o abade L'Epée, que como destaca Perlin (2002)

O abade L'Epée foi um dos grandes responsáveis por essas mudanças, mesmo que tivesse conhecido a língua de sinais quanto tinha em torno de sessenta anos de idade. $\mathrm{O}$ abade reuniu os surdos pobres dos arredores de Paris e criou a primeira escola pública para surdos, provavelmente influenciada pelos ideais da Revolução Francesa. Foi nesse espaço educativo que se iniciou o uso da língua de sinais (PERLIN, 2002, p. 37).

Com isso, foram obtidos resultados positivos na educação dos surdos e eles passaram a exercer a sua cidadania de forma mais plena, principalmente pelo uso da língua de sinais, e o modelo utilizado por L'Epée foi tão bem sucedido e aceito que foi replicado para outros países, ocasionando a criação de escolas de surdos ao redor do mundo e a formação, pelo instituto de L'Epée, de professores surdos que difundiriam posteriormente o uso da língua de sinais pelos sujeitos surdos.

As escolas fundadas em outros países, nos moldes da França, passaram a usar as línguas de sinais nacionais e a explorar novos recursos na educação de surdos. O currículo da escola para surdos, em Paris, passou a conter língua de sinais, religião, língua nacional e formação profissional (PERLIN, 2002, p. 38). 
Com o uso da língua de sinais ocorre a valorização desta para uso por sujeitos surdos, e com isso cresce a quantidade de surdos instruídos e usuários dessa língua. No decorrer dos anos, iniciam trabalhos que visam colocar em prática métodos para instruir os surdos, que acabam por se destacar dois deles, sendo o um o que já observamos anteriormente, como o uso da língua de sinais, e outro que defendia unicamente a predominância da voz, que é o oralismo, que foi introduzido por Samuel Heinicke.

Esse método tem como ideia central a patologia crônica do surdo. Essa patologia pode ser traduzida como lesão no canal auditivo que obstaculiza a aquisição da língua. Segundo Heinicke, que era médico, as intervenções clínicas poderiam corrigir e induzir o surdo ao uso da fala (PERLIN, 2002, p. 41).

Esse método entra em conflito com o método utilizado por L'Epée, onde no oralismo a utilização da língua de sinais é proibida, sendo vista como "inimiga” do método oral.

Os profissionais do oralismo, ao longo da história da educação de surdos, têm usado, em maior ou menor grau, as determinações desse médico. Gestos ou sinais de qualquer natureza eram considerados como caminhos para a língua de sinais, portanto eram expressamente proibidos (PERLIN, 2002, p. 41).

Com isso, podemos notar que prevalecem duas representações a respeito dos surdos e da surdez, que conforme são apontadas por Santana (2007) dividem os pesquisadores e profissionais que atuam com os surdos, entre os que tem uma representação clínica da surdez o os que vêem os surdos como sujeitos com uma diferença cultural.

Nessa concepção clínica da surdez, esta é vista como uma deficiência, como algo a ser tratado, corrigido. Dentro dessa representação do surdo como deficiente todas as atitudes, educacionais e sociais, tem como foco a audição, e com isso são realizadas intervenções médicas, terapias fonoaudiológicas a fim de aumentar a capacidade auditiva, corrigir alguma "anomalia" no canal auditivo ou para treinar habilidades de leitura labial e reprodução dos sons da fala.

Em contrapartida, uma outra concepção não leva em consideração a surdez como deficiência, mas sim como uma diferença cultural, o que, conforme Skliar (1998) torna possível que o sujeito surdo construa sua subjetividade através de experiências mediadas pela língua de sinais como forma de concretização de uma comunicação simbólica.

Os estudos recentes sobre os surdos e a sua constituição como sujeitos culturais perpassa pelos conceitos da inclusão de todos os indivíduos na sociedade, o que quebra o que vinha sendo 
difundido em larga escala na sociedade, que "gerou o desejo da necessidade de sermos perfeitos para pertencermos a ela, senão estaríamos excluídos” (STROBEL, 2008, p. 16)

Saindo desse discurso de que "o sujeito surdo para estar bem integrado à sociedade, deveria se adaptar à cultura ouvinte, porque somente assim poderia viver 'normalmente'. Se não conseguir, é considerado "desviante", os pesquisadores apontam para a existência de uma cultura surda, uma cultura que valoriza as experiências vividas pelos surdos na sua constituição como sujeito.

Cultura surda é o jeito de o sujeito surdo entender o mundo e de modifica-lo a fim de torna-lo acessível e habitável ajustando-os com as suas percepções visuais, que contribuem para a definição das identidades surdas e das 'almas' das comunidades surdas. Isto significa que abrange a língua, as ideias, as crenças, os costumes e os hábitos de povo surdo (STOBEL, 2008, p. 24).

Em função disso, nas disciplinas que foram introduzidas nos cursos de licenciatura pelo Decreto $n^{\circ} 5.626$ (BRASIL, 2005), tem como função apresentar um dos artefatos culturais dos surdos, que é a língua de sinais, como língua utilizada pela comunidade surda para se comunicar, para apreender do mundo e para modifica-lo, sendo que essa língua se constitui como principal forma de participação dos surdos enquanto cidadãos produtivos e participantes de uma sociedade maior.

Assim, os alunos da disciplina de Libras, nos cursos de Licenciatura precisam conhecer esses aspectos da constituição do sujeito surdo como um sujeito que apresenta uma diferença cultural, com uma língua diferente, como experiência diferentes e com capacidade e habilidade de aprendizado e de participação no ambiente que está, e mais especificamente no ambiente escolar, onde esses futuros docentes terão contato mais direto com estes sujeitos.

\section{Metodologia}

Para que pudéssemos apreender como futuros professores percebem o surdo e a Libras, foi realizado este estudo a partir de uma abordagem qualitativa, em função de se considerar que existe uma relação direta e dinâmica entre os sujeitos e o mundo real. Há um vínculo indissociável entre a subjetividade do sujeito e o mundo objetivo, e isto não pode ser traduzido de forma numérica. Além disso, aponta-se para a característica descritiva das pesquisas de abordagem qualitativa, onde o processo e o significado que é atribuído pelos sujeitos para determinados processos e elementos do seu contexto são o foco principal desta abordagem (KAUARK; MANHÃES; MEDEIROS, 2010). 
Escolhemos realizar esta pesquisa em formato de estudo de caso, por ser apresentar como um conjunto de procedimentos que permitem compreender uma determinada relação de causa e efeito para um fenômeno (MALHEIROS, 2011). Como temos como objetivos analisar as mudanças na forma de perceber dos futuros professores sobre o surdo e a Libras, fazendo uma análise comparativa entre o antes e o depois da disciplina de Libras, a escolha do estudo de caso nos parece apropriada.

Assim, este estudo de caso se desenvolve em uma Universidade pública do estado do Rio de Janeiro, com graduandos dos cursos de Licenciatura em Pedagogia e Licenciatura em Geografia. Temos como objetivos específicos apresentar as percepções dos alunos de licenciatura a respeito dos surdos e da Libras antes de cursarem a disciplina de Libras; apresentar as percepções dos alunos de licenciatura a respeito dos surdos e da Libras depois de cursarem a disciplina de Libras; e analisar a mudança das formas de perceber dos alunos acerca dos surdos e da Libras. O perfil dos participantes é apresentado no quadro a seguir

Quadro 1 - Perfil dos participantes

\begin{tabular}{|l|l|l|l|}
\hline \multicolumn{1}{|c|}{ Nome* } & \multicolumn{1}{c|}{$\begin{array}{c}\text { Cursou a } \\
\text { disciplina? }\end{array}$} & \multicolumn{1}{c|}{ Curso } & \multicolumn{1}{c|}{} \\
\hline Aline & Não & Pedagogia & $1^{\circ}$ semestre \\
\hline Miguel & Não & Geografia & $3^{\circ}$ semestre \\
\hline Rute & Não & Pedagogia & $1^{\mathbf{o}}$ semestre \\
\hline Vanessa & Não & Pedagogia & $1^{\mathbf{o}}$ semestre \\
\hline Carla & Sim & Pedagogia & $7^{\mathbf{o}}$ semestre \\
\hline Gisele & Sim & Pedagogia & $9^{\mathbf{o}}$ semestre \\
\hline Israel & Sim & Geografia & $3^{\mathbf{o}}$ semestre \\
\hline Lucia & Sim & Pedagogia & $3^{\circ}$ semestre \\
\hline Roberta & Sim & Geografia & $3^{\circ}$ semestre \\
\hline Sara & Sim & Pedagogia & $7^{\circ}$ semestre \\
\hline
\end{tabular}

Fonte: Elaboração do autor ( 2017).

* Os nomes são ficticios.

Por termos o estudo de caso como formato deste estudo, que se constitui como um "estudo profundo e exaustivo de um ou poucos objetos de maneira que se permita o seu amplo e detalhado conhecimento" (KAUARK; MANHÃES; MEDEIROS, 2010, p. 29), realizamos a coleta de dados por meio de entrevista semiestruturada. Essa forma de entrevista combina "perguntas abertas e fechadas, onde o informante tem a possibilidade de discorrer sobre o tema proposto" (BONI; QUARESMA, 2005, p. 75). Participaram da pesquisa 10 alunos dos referidos cursos, sendo que 4 ainda não cursaram a disciplina e 6 já cursaram a disciplina. 
Após as entrevistas, as falas foram transcritas e analisadas utilizando a abordagem da análise de conteúdo, baseado em Bardin (2011), que consiste em

\begin{abstract}
um conjunto de técnicas de análise das comunicações visando a obter, por procedimentos sistemáticos e objetivos de descrição do conteúdo das mensagens, indicadores (quantitativos ou não) que permitam a inferência de conhecimentos relativos às condições de produção/recepção (variáveis inferidas) destas mensagens (BARDIN, 2011, p. 47).
\end{abstract}

Seguimos as fases propostas por Bardin (2011) para a realização da análise, que foram a pré-análise, a exploração do material e tratamento dos resultados (inferência e interpretação). Os resultados foram organizados em categorias temáticas, que são "fatores, aspectos, elementos do fato ou situação em estudo, que são classificados e reunidos em eixos ou unidades temáticas a partir e com os dados coletados" (OLIVEIRA; MOTA NETO, 2011, p. 164). Assim, são apresentados a seguir dois eixos definidos para organizar os dados, a partir de temas que se aglutinam em determinadas formas de perceber o surdo e a Libras.

Neste artigo serão apresentadas algumas das percepções desses alunos, sendo que nem todas as respostas serão transcritas, uma vez que algumas delas tem um conteúdo muito similar e serão representadas por apenas uma resposta a fim de não ser repetitivo na apresentação dos resultados. Os dois eixos/categorias são: percepção clinico terapêutica antes da disciplina e percepção sócio antropológica depois da disciplina.

\title{
A percepção clinico terapêutica antes da disciplina
}

Durante a realização dessa pesquisa, realizamos entrevistas com alunos dos cursos de Licenciatura em Pedagogia e Licenciatura em Geografia, e obtivemos respostas a respeito das percepções destes sobre o surdo, sobre a Libras, e sobre as suas expectativas em relação a disciplina de Libras.

No que tange a percepção destes a respeito do surdo, podemos observar que estes apesentavam uma visão clínico terapêutica, e isso fica bem demarcado na resposta de Miguel, que diz que "o conceito de surdez acho que é um deficiente auditivo" (entrevista realizada em 17/03/2016).

Essa perspectiva clínico terapêutica é caracterizada por essa característica de demarcar o surdo como um indivíduo inferior, incompleto, como apontado por Lopes (2012)

A representação clinicoterapêutica entende os surdos como deficientes e os classifica segundo graus de perda de audição. Nessa representação, o surdo é visto como um sujeito inferior, incompleto, que deve ter sua deficiência removida através de terapias da 
fala e sessões de oralização, a fim de que se pareça, o mais possível, com os que ouvem. A representação clinicoterapêutica nega, assim, a existência das identidades e da diferença surda (LOPES, 2012, p. 157).

Essa visão também está presenta na fala de Rute, que apesar de não demarcar o surdo como deficiente, aponta que é uma pessoa com mais dificuldades que os ouvintes.

Eu não tenho uma espécie de preconceito, até porque eu tive algumas explicações sobre e eu acompanho um pouquinho na internet, por curiosidade e afins, então surdo é só um título, a meu ver é só um título, por que ele é uma pessoa normal, assim como todos nós, só que com um pouquinho mais de dificuldade do que nós, uma dependência mais do que nós (entrevista realizada em 18/03/2016).

Assim como Aline e Vanessa, que apontam o surdo como uma pessoa que tem dificuldades, quando dizem:

\begin{abstract}
Aline: São pessoas que tem algum grau de dificuldade para escutar, e tem uns que são $100 \%$ e os que não são.

Vanessa: Eu não diria bem deficiente, mas uma pessoa com dificuldade para entrar na sociedade, que hoje em dia estão até melhor, porque antigamente a situação deles era mais crítica, porém tem evoluído bastante o conceito. Não é bem deficiente, nem anormal, mas uma pessoa com dificuldade apenas (entrevistas realizadas em 17/03/2016).
\end{abstract}

Podemos notar nessas respostas que além de classificar o surdo como deficiente, tendo um olhar de algo que "falta" a este sujeito, na maioria das respostas ficou marcada a dificuldade que, aparentemente, o surdo tem, colocando a responsabilidade para o sujeito, e não para a sociedade. Podemos observar nisso a presença no "ouvintismo", ou seja, "conjunto de representações dos ouvintes, a partir do qual o surdo está obrigado a olhar-se e narrar-se como se fosse ouvinte" (SKLIAR, 1998, p. 15).

Notamos que é a percepção que os entrevistados apresentam é de que o surdo que tem problemas para se comunicar, que ele que apresenta as dificuldades, quando o que poderia ser visto é que a sociedade não está preparada para se comunicar com ele, o que demonstra a visão da sociedade do que não está dentro dos "ideais" para uma sociedade homogênea. Gesser (2009) aponta isso quando trata da visão negativa que a sociedade tem a respeito da surdez, quando diz que:

Na nossa sociedade, portanto, ser 'normal' é ser homem, branco, ocidental, letrado, heterossexual, usuário de língua oral padrão, ouvinte, não cadeirante, vidente, sem 'desvios' cognitivos, mentais e/ou sociais (GESSER, 2009, p. 68). 
Ainda a este respeito, Santana (2007) aponta que essas normas colocadas pela sociedade nos fazem imputar ao surdo essa dificuldade, tirando do restante da sociedade a necessidade de adequação para aceitação do sujeito como diferente.

Assim, vemos que as normas sociais - organizadoras de toda a nossa vida social (modos de falar, de se vestir, de atuar no mundo, de pensar etc.) - "autorizam" a segregação. A forma como a surdez é descrita está ideologicamente relacionada com essa normas (SANTANA, 2007, p. 32).

Ainda sobre a surdez, foi questionado aos futuros professores qual a percepção deles em relação a Libras - Língua Brasileira de Sinais, então ficou claro nas respostas dos participantes que a Libras é uma linguagem, ou uma forma de comunicação. Podemos observar na resposta de Rute, que mesmo identificando a Libras como um outro idioma, ela tem um conceito que não reflete a realidade desta língua.

O que eu sei é que Libras é um idioma, né, um outro idioma, eu acho difícil, assim, para construir frases, eu não sei construir frases, mas algumas letras eu sei fazer, números eu sei fazer, mas não acho um bicho de sete cabeças não, até porque é uma língua latina, é o nosso português e é só uma dificuldade inicial de posição de mão, a expressão, por que a gente usa muito expressão, mas não acho um bicho se sete cabeças, que ninguém possa aprender (entrevista realizada em 18/03/2016).

Podemos notar que Rute acredita que a Libras é uma representação em sinais da língua portuguesa, mas sabe-se que isso é uma percepção equivoca, pois Gesser (2009) já desmistifica essa afirmação de que a Libras é apenas o português sinalizado, quando afirma que "a língua de sinais tem estrutura própria, e é autônoma, ou seja, independente de qualquer língua oral em sua concepção linguística" (GESSER, 2009, p. 33).

Essa percepção que não identifica a Libras como uma língua legítima está de acordo com as falas anteriores que colocam o surdo com dificuldades, pois como Santana (2007, p. 33) aponta que "ser anormal é caracterizado pela ausência da língua e de tudo que ela representa (comunicação, pensamento, aprendizagem, etc)".

Ainda entre os futuros professores que ainda não tiveram a disciplina de Libras, entre as respostas sobre o que esperam aprender na disciplina de Libras, mais uma vez podemos notar na fala destes que a percepção que tem do surdo não é se um sujeito, dentro dos padrões de normalidade aceitos pela sociedade. Miguel nos responde a esta pergunta:

O básico, assim, de linguagem, que deve ter sobre Libras e o conteúdo mais da parte de Leis, que deve ter, eu acho, e nessa questão de até mesmo o deficiente auditivo dentro de uma sala de aula junto com os alunos normais, como se deve lidar com ele se tem alguma lei específica para isso ou não (entrevista realizada em 17/03/2016). 
Isso está de acordo com o discurso binário de normal/anormal, que permeia nossa sociedade por décadas e que se reflete nas práticas educativas que eram praticadas anteriormente a utilização da perspectiva inclusiva na educação básica no Brasil, a partir do final da década de década de 1990 e início da década de 2000.

Isto é corroborado por Lunardi (2005) quando aponta esses discursos:

Os discursos, ao redor e dentro dos quais se produzem as noções de normalidade em torno dos sujeitos surdos, estão estruturados a partir de algumas dicotomias ou oposições binárias - ouvinte/surdo, língua oral/língua de sinais, deficiência/diferença, normalidade/anormalidade, minoria/maioria, saúde/enfermidade - que colocam, de um lado, um termo dominante que acaba funcionando como referência e que, por sua vez, só pode ser sustentado pelo segundo, que significa a falta ou a negação (LUNARDI, 2005, p. 3).

Desta forma, a mudança destas percepções deve acontecer, mas não é algo que ocorra de forma imediata, é preciso tempo para que essas mudanças tenham efeito nas percepções que os sujeitos dessa sociedade, em especial os educadores, tem a respeito dos surdos e da Libras, e isso perpassa pela disciplina de Libras e pelos conteúdos abordados durante as aulas, pois, como Santana (2007, p. 33) aponta é "a partir do momento em que se tem a língua de sinais como língua do surdo, o padrão de normalidade também muda", uma vez que "a língua de sinais legitima o surdo como 'sujeito de linguagem' e é capaz de transformar a 'anormalidade' em diferença" (SANTANA, 2007, p. 33).

\section{A percepção sócio antropológica depois da disciplina}

Em função do exposto anteriormente, foram entrevistados professores em formação que já haviam cursado a disciplina de Libras, que teve entre os temas abordados conteúdos que levavam em consideração uma visão sócio antropológica do surdo, abordando a ideia da surdez com diferença, e não como deficiência, e como Santana (2007, p. 33) aponta "a ideia de que a surdez é uma diferença traz com ela uma delimitação de esferas sociais: a identidade surda, a cultura surda, a comunidade surda”.

No que diz respeito a como percebem o sujeito surdo, e quando perguntados sobre isso, podemos observar nas respostas dos entrevistados que sua visão já demarca a diferença, e não mais a deficiência, como podemos ver na resposta de Roberta:

Eu tenho como uma pessoa muito mais ágil e dinâmica do que eu achava que era, porque eu tinha uma certa barreira de achar que eles tinham dificuldades, de que eles eram "coitadinhos", e hoje em dia não, vejo que são pessoas como nós, só tem uma 
pequena diferença, mas fazem tudo como a gente, tem toda capacidade como a gente (entrevista realizada em 16/03/2016).

Podemos observar que a entrevistada relata a sua mudança na percepção, que agora não tem mais a visão de "coitadinhos" ou de pessoas com dificuldades, mas de sujeitos que apresentam uma diferença e que tem a mesma capacidade que os ouvintes.

Ainda Israel nos aponta que, mesmo considerando um surdo como deficiente, este tem seu lugar na sociedade.

O conceito que eu tenho do surdo é o fato de não julgar pelo estereótipo, pelo fato de ele não ter audição, mas ao mesmo tempo não fazer com que ele não deixe der uma pessoa social, eu penso que o surdo é aquela pessoa que através da deficiência, apesar da deficiência, ele tem sim o seu local certo, reservado, no meio social (entrevista realizada em 16/03/2016).

Com isso, vemos a presença do mesmo discurso assumido por surdos que usam a língua de sinais, tendo uma perspectiva sócio antropológica da surdez, que se constitui como Lopes (2012) descreve:

Esses, vêem a surdez a partir de uma representação socioantropológica, representação que os narra como sujeitos pertencentes a um grupo cultural e linguístico minoritário. Nessa representação, os surdos constituem uma comunidade linguística e cultural minoritária, constituída por sujeitos que possuem uma cultura visual, para o entendimento e apreensão do mundo (LOPES, 2012, p. 164).

Para Israel é importante que Libras e o contato com a temática da inclusão estejam presente em todos os espaços e níveis educacionais, não apenas nas licenciaturas.

Eu penso que a Libras é de certa forma um meio de comunicação e que deveria ser mais explorado não só dentro das universidades mas também na educação primária, secundária, eu penso que ainda há muito a se fazer, por que aqui dentro da faculdade nós temos uma visão, eu aprendi muita coisa na matéria, na disciplina, e passei a ter uma concepção que eu não tinha, que eu não tive lá atrás no ensino, então penso que deveria ser mais explorado, por que é preciso, o professor hoje ele precisa sim saber como lidar com o aluno com deficiência, não apenas no sentido do surdo, mas de outros também, como os cegos, entre outros (entrevista realizada em 16/03/2016).

Sara também salienta a necessidade de não apenas os alunos desta disciplina, e consequentemente futuros professores, de terem essa visão, mas de receber apoio dos outros integrantes da escola onde o aluno surdo esteja presente.

O que acontece, a gente sabe que existe uma população significativa, e apesar de a gente não enxergar, e é interessante isso, e a disciplina ela propôs ao aluno uma aproximação desse universo, quebrando barreiras primeiramente, talvez o profissional 
dentro de sala de aula ele se veja impossibilitado de receber esse aluno, pois é muito mais prático na oralidade do que dentro dos sinais, como vai se apropriar, como vai ajudar esse aluno, e talvez no seu decorrer do dia, da jornada do cotidiano jogar ele pro escanteio, e mediante a disciplina não, facilitou, dando amplitude de como trabalhar, não é tão difícil assim, não é tão complicado, mas é necessário que a escola, a comunidade escolar esteja de portas abertas, auxiliando o professor com recursos, nos seus planejamento de aulas, dando vazão a esse aluno (entrevista realizada em 17/03/2016).

Esse é um ponto relevante levantado por Sara, apontando para uma importante mudança em sua visão. Isto também pode influenciar mudanças maiores por meio de formar diferentes de agir no ambiente escolar, uma vez que no contexto social, "a escola é um dos espaços privilegiados, espaço socialmente legitimado para a construção e a reconstrução das subjetividades, é o espaço onde a cultura difunde e se recria" (OLIVEIRA, 2010, p. 4), ou seja, a escola é responsável por mudar a percepção que a sociedade tem a respeito de determinados assuntos e determinados sujeitos, e por este motivo, a visão dos futuros professores acerca do surdo, tendo uma concepção de sujeito diferente, influenciará em como a sociedade perceberá também o sujeito surdo.

Para que essa visão apresente uma certa materialidade, é preciso que esses professores também tenham uma percepção diferenciada a respeito da língua utilizada pelos surdos, que no Brasil é a Libras. A esse respeito, quando questionados sobre isso, qual a percepção que eles têm a respeito da Libras, tivemos diversas respostas. Carla nos mostrou isso ao dizer:

\footnotetext{
Hoje eu entendo que é a segunda língua oficial do país, e que a gente não sabe nada, a gente não se importa, outro dia, eu tenho alunos adolescentes e a gente estava falando da importância de se falar inglês, que é uma língua universal e que a gente precisa falar inglês, e um aluno virou e falou assim pra mim: "mas professora, a gente não sabe nem a segunda língua oficial do nosso país que é a Libras, como é que exigem da gente que a gente saiba falar inglês", e hoje eu vejo que é uma coisa que a gente tem de muito importante mas que a gente não sabe. É uma visão diferente que a gente não sabia, não sabia nem que era a segunda língua oficial, eu fiquei sabendo depois da disciplina, e se não fosse isso eu não saberia (entrevista realizada no dia 15/03/2016).
}

Ao considerar a Libras como língua, reconhece-se que ela possui elementos inerentes às demais línguas orais, apresentando, como apontado por Gesser (2009) aspectos fonológicos e morfológicos, entre outros, que a caracterizam com o estatuto de língua. Ainda Gesser aponta que a crença de que a língua de sinais não tem estatuto de língua está ancorado na não credibilidade de que ela possui uma gramática, e muito desse pensamento vem de a maioria dos ouvintes acreditarem que as línguas de sinais não passam de mímicas ou pantomimas. 
Esse tipo de pensamento que Gesser (2009) aponta da maioria ouvinte vai além de apenas uma confusão, como a própria autora descreve:

Quando me perguntam, entretanto, se a língua de sinais é mímica, entendo que está implícito nessa pergunta um preconceito muito grave, que vai além da discussão sobre a legitimidade linguística ou mesmo sobre quaisquer relações que ela possa ter (ou não) com a língua de sinais. Está associada a essa pergunta a ideia que muitos ouvintes têm sobre os surdos: uma visão embasada na anormalidade, segundo a qual o máximo que o surdo consegue expressar é uma forma pantomímica indecifrável e somente compreensível entre eles. Não à toa, as nomeações pejorativas anormal, deficiente, débil mental, mudo, surdo mudo, mudinho têm sido equivocadamente atribuídas a esses indivíduos (GESSER, 2009, p. 21).

Neste sentido, podemos observar na resposta de Sara a não existência desse preconceito, quando ela fala sobre sua percepção a respeito da Libras:

Muito mais do que um gesto, que isso ficou bem frisado em algum texto, que não é apenas um gesto, é um código de sinais, em que é possível expressar tudo, através dos sentimentos, conceitos, até coisas abstratas, isso a gente acha que é algo impossível, mas é sim, parece algo complexo, mas acho que quando a gente vai se aproximando vai se desmistificando, e aquilo que é tão escuro vai clareando, se tornando mais fácil (entrevista realizada em 17/03/2016).

A resposta de Sara também apresenta um dos aspectos que Gesser (2009) aborda em sua obra, quando trata sobre o que pode ser expresso em língua de sinais:

\begin{abstract}
Assim, é correto afirmar que as pessoas que falam línguas de sinais expressam sentimentos, emoções, e quaisquer ideias ou conceitos abstratos. Tal como os falantes de línguas orais, os falantes de línguas de sinais podem discutir filosofia, política, literatura, assuntos cotidianos etc. nessa língua, além de transitar por diversos gêneros discursivos, criar poesias, fazer apresentações acadêmicas, peças teatrais, contar e inventar histórias e piadas, por exemplo (GESSER, 2009, p. 23).
\end{abstract}

Desta forma, o resultado que a disciplina teve sobre a percepção desses sujeitos em relação ao surdo e a Libras foi positivo, uma vez que em suas respostas não encontramos essas marcas do preconceito, mesmo que não totalmente explícito o reconhecimento da Libras como língua.

Quando questionados a respeito da importância da disciplina, Lucia aponta para uma atividade realizada, que foi assistir a um filme e fazer relação dos eventos apresentados no filme com os textos trabalhados na disciplina a respeito dos momentos e abordagens da educação de 
surdos. O filme em questão foi "E seu nome é Jonas" ${ }^{1}$. Lucia aponta para a relevância da atividade e a relação com seu cotidiano profissional.

O filme do Jonas por que a mãe não estava sabendo lidar com a deficiência do filho e ai ela foi pra uma escola e eles estavam "não ele vai ter que falar e isso e aquilo" e forçando a criança, sendo que na verdade quando ela foi pro mundo do filho ai que ela viu que não era demente, ele não tinha... era só a surdez e depois eles conseguiram se comunicar, e assim, eu me identifiquei pelo fato de aonde eu trabalho, esse ano a gente está com 10 crianças especiais, então assim, vamos falar a verdade, as crianças lá elas ficam no mundo delas ela chega e dá um papel pra desenhar, deixa ela ficar andando pela sala, então assim, não tem uma pessoa específica pra criança, por que a gente tem criança com síndrome de Down, autista, cadeirante, cadeirante que tem dificuldade na fala, então eu me identifiquei muito com o filme e com Libras, que uma forma de integrar a criança (entrevista realizada em 17/03/2016).

Outra resposta que nos chamou atenção foi a de Gisele, pois a entrevistada, em poucas palavras, aponta o quanto a disciplina lhe ampliou as possibilidades entre o que é possível e o que é impossível. Gisele nos respondeu a essa pergunta:

É possível a inclusão, é possível aprender, tudo é possível, quem não acha que não é possível, é! E a gente aprende com eles é o melhor disso tudo é a troca da aprendizagem, é uma troca (entrevista realizada em 17/03/2016).

O reconhecimento da entrevistada dessa possibilidade nos mostra que as mudanças da percepção da sociedade são possíveis, mesmo que sendo algo demorado e trabalhoso, mas ao vislumbrarmos essa possibilidade presente no discurso de uma futura professora nos faz pensa no que Santana (2007) nos diz:

Fazer que a surdez passe de doença à diferença não é uma simples mudança de ponto de vista; para isso é necessário estabelecer novas normas, o que não é imediato, já que implica mudanças sociais decorrentes da alteração dos padrões ao longo da história (SANTANA, 2007, p. 32).

Assim, conseguimos perceber que a percepção dos alunos após a disciplina apresenta características que reconhecem o surdo como um sujeito diferente, e não como deficiente, e que a sua língua é marca dessa diferença, e principalmente, a utilização desta língua pelos professores é o que demarca o reconhecimento dessa diferença enquanto sujeito.

\section{Considerações Finais}

\footnotetext{
${ }^{1}$ E seu nome é Jonas. Título original: And your name is Jonah. Dirigido por Richard Michaels, escrito por Michael Bortman. EUA: MGM, 1979. 100 min. Disponível em <https://www.youtube.com/watch?v=jPHIDcPxjx8 $>$.
} 
Neste presente trabalho, podemos notar que a percepção dos futuros professores a respeito do surdo e da Libras sofre mudanças em função de cursarem a disciplina de Libras durante o seu processo de formação.

Notamos nas falas dos que ainda não cursaram a disciplina uma perspectiva clínico terapêutica da surdez, marcada principalmente por verem o surdo como deficiente e que a sua forma de comunicação, a Libras, tem uma característica apenas de representação em sinais da língua oral. Ambos conceitos não são formados por preconceito somente dos entrevistados, mas por uma construção em função do meio social, que tem a mesma percepção.

Após cursarem a disciplina e observarem uma nova perspectiva sobre a surdez, uma perspectiva sócio antropológica é identificada nas falas dos entrevistados, reconhecendo o surdo com um sujeito que se constitui social, cultural e linguisticamente diferente, além de perceber a sua forma de expressão, a Libras, como uma língua, que apresenta possibilidades infinitas de expressão e que constitui a língua desta comunidade.

Com isso, notamos a relevância da disciplina de Libras nos cursos de Licenciaturas, uma vez que essa visão do surdo como sujeitos diferentes presente nestes futuros educadores, se constitui como meio de difusão do reconhecimento linguístico, cultural e social do surdo, e principalmente pela presença desta perspectiva na escola, a mesma se constitui como formadora de cidadãos que terão essa percepção, e isso resulta numa sociedade que aceita o surdo como sujeito diferente.

\section{Referências}

BARDIN, Laurence. Análise de conteúdo. São Paulo: Edições 70, 2011.

BRASIL. Decreto $n^{o} 5.626$, de 22 de dezembro de 2005. Regulamenta a Lei no 10.436, de 24 de abril de 2002, que dispõe sobre a Língua Brasileira de Sinais - Libras, e o art. 18 da Lei no 10.098, de 19 de dezembro de 2000. Disponível em <http://www.planalto.gov.br/ccivil_03/_ato2004-2006/2005/decreto/d5626.htm>. Acesso em 10 jul 2017.

BONI, Valdete; QUARESMA, Sílvia Jurema. Aprendendo a entrevistar: como fazer entrevistas em Ciências Sociais. Revista Eletrônica de Pós-Graduandos em Sociologia Política da UFSC. V. 2. N. 1 (3). jan/jul. 2005, p. 68-80.

GESSER, Audrei. LIBRAS: que língua é essa? crenças e preconceitos em torno da língua de sinais e da realidade surda. São Paulo: Parábola Editorial. 2009.

KAUARK, Fabiana da Silva; MANHÃES, Fernanda Castro; MEDEIROS, Carlos Henrique. Metodologia de pesquisa: um guia prático. Itabuna: Via Litterarum. 2010. 
LOPES, Maura Corcini (org.). Cultura surda e Libras. São Leopoldo: Unisinos, 2012.

LUNARDI, Márcia Lise. Surdez: tratar de incluir, tratar de normalizar. Revista Educação Especial. No 26. 2005. p. 117-130. Disponível em <https://periodicos.ufsm.br/educacaoespecial/article/view/4406/2579>. Acesso em 20 jun 2017.

MALHEIROS, Bruno Taranto. Metodologia da pesquisa em educação. Rio de Janeiro: LTC, 2011.

OLIVEIRA, Amanda Melissa Bariano de. As barreiras e as oportunidades de inclusão do surdo no ensino regular. II Simposio Nacional de Educação. XXI Semana de Pedagogia: Infância, Sociedade e Educação. Campus de Cascavel, Out 2010. Disponível em <http://cacphp.unioeste.br/eventos/iisimposioeducacao/anais/trabalhos/15.pdf>. Acesso em 21 jun 2017.

OLIVEIRA, Ivanilde Apoluceno de; MOTA NETO, João Colares da. A construção de categorias de análise na pesquisa em educação. In: MARCONDES, Maria Inês; OLIVEIRA, Ivanilde Apoluceno de; TEIXEIRA, Elizabeth. Abordagens teóricas e construções metodológicas na pesquisa em educação. Belém: EDUEPA, 2011. p. 161-179.

PERLIN, Gladis. História dos surdos. Florianópolis: UDESC/CEAD, 2002.

SANTANA, Ana Paula. Surdez e linguagem: aspectos e implicações neurolinguísticas. São Paulo: Plexus. 2007.

SKLIAR, Carlos (org.). A surdez: um olhar sobre as diferenças. Porto Alegre: Mediação,1998.

STROBEL, Karin. As imagens do outro sobre a cultura surda. Florianópolis: Editora da UFSC, 2008.

${ }^{\text {i }}$ Professor de Libras da Faculdade de Educação da baixada fluminense da Universidade do Estado do Rio de Janeiro (FEBEF/UERJ) 